\title{
Nuevas propuestas pedagógicas y el papel social del docente
}

\author{
Maurizia D'Antoni
}

En momentos históricos que nos muestran un mundo que cambia bajo nuestros ojos, y con una velocidad impresionante, nos preguntamos de qué manera los cambios, a su vez, nos están cambiando. Se ha dicho (Jameson, 1998) que tal vez lo más importante que podamos hacer es no dejarnos seducir por los significados conocidos, el sentido "congelado", los viejos senderos sabidos y "clásicos" de la teoría.

En efecto, esa vieja teoría no representa lo que sucede en nuestros tiempos, su velocidad, a veces su contradictoriedad. Es por ello que probablemente nosotros, como científicos sociales o como trabajadores de la educación tendríamos que dedicar nuestros esfuerzos a mantenernos abiertos, a estar "en el flujo" de las cosas, a olvidar más que a recordar las lecciones recibidas por las Universidades en las que nos formamos.

Las instituciones que conocimos fueron construidas para otros intereses y exigencias, para servir en el contexto 
de un mundo diferente: de querer aferrarnos a su forma consoladora, sucumbiríamos a la angustia. De la misma mane$\mathrm{ra}$, las instituciones escolares se fundaron para servir a las clases dominantes latinoamericanas en su proyecto de afirmación y de adaptación a la modernidad; sin embargo, ese mismo modelo de futuro, implícito en las políticas educativas, hoy ha sido superado.

Mejor recordar que "crisis", esta crisis de la escuela de la que se habla, puede ser más que un fin, un re comienzo:: nos lo prueban las contribuciones teóricas, más vivas que nunca, que consideramos nuestras aliadas en la tarea de renovación.

Identificamos, a la vez, una crisis en la que entran las "autoridades", los roles de identidad y de poder en lo que se ha llamado el posmodernismo. El papel del hombre sobre la mujer, de los mayores sobre los jóvenes, del hombre blanco sobre los demás colores y de los maestros sobre sus discípulos está siendo cuestionado y repensado, de una manera que todavía no nos resulta terminada y coherente.

Los poderes tradicionales sucumben ante los cambios históricos y sociales y los movimientos que demandan justicia, igualdad y derechos. Se oponen a esas luchas, con arrogancia, las grandes narrativas que recalcan el control y el dominio (Giroux, 1992 pag. 56). En una eterna dialéctica, a esas voces del control y del dominio le responde la búsqueda de una nueva racionalidad y un renacimiento de la confianza, relativa, en las posibilidades humanas de analizar y comprender las cosas, de la creatividad y de una individualidad que tiene una razón de ser sistémica más que biológica.

En cuanto al papel del maestro, algunos autores, desde Antonio Gramsci a Giroux, a McLaren, sienten la exigencia de reflexionar acerca del destino de los trabajadores culturales y de los trabajadores de la educación en los mo- 
mentos de cambio, momentos en los que varios países, en cuenta Costa Rica, se están proponiendo actuar en pro de una reforma educativa.

\section{En esta guerra, no hay desertores}

Durante la campaña presidencial que desembocó en las controversiales elecciones del febrero 2006, se ha escuchado como algunos de los candidatos presidenciales se han referido al problema de la "deserción escolar" y a la necesidad de intervenir al respecto.

Preocupa pensar el "cómo" se realice esa intervención, a partir de qué elementos y con la colaboración de cuáles actores.

Preocupa también el término escogido por los entonces asesores presidenciales, el de "deserción", que nos refiere de inmediato a un ejército en desbandada y a unos soldados culpables de traición de su causa patria. En tiempos de guerra en muchos países, aún países considerados "democráticos", los desertores son posibles de ser fusilados en el acto, ya que se considera que fomentar el desorden, la ruptura de las jerarquías, la desobediencia, merece la pena de muerte en momentos de "crisis" bélica.

La evitación del término "desertores" parece necesaria en momentos en que las investigaciones, toman en cuenta las entidades que trabajan en ámbito cercano a la oficialidad, como por ejemplo el Proyecto Estado de la Nación, indican la presencia de un enorme número de estudiantes excluidos de la escuela secundaria: Las investigaciones oficiales confirman lo que dicen acerca de las causas del fenómeno el sentido común y la observación de los que están cerca de la institución escolar: el proceso de exclusión es poli causal, la pobreza y la distancia entre contenidos, metodologías y estudiantes son unas de las causas más so- 
bresalientes. La pobreza, la falta de apoyo, la distancia entre los intereses y las necesidades de los jóvenes, las "clases aburridas", la falta de acompañamiento adecuado en el paso de la primaria a la secundaria son algunos de los factores que se subrayan (Estado de la educación, 2006, pág.27). A partir de estos datos, el abusado término de "desertores" se vuelve más y más contradictorio.

Las afirmaciones y los estudios oficiales sobre los estudiantes, por lo menos les dedican una mirada, casi como si fueran el virus que causan la enfermedad. Se aprecian aún menos contribuciones y aún menos agudas acerca del papel de los docentes.

Se cree oportuno, por lo tanto, que se le agregue a la discusión actualmente existente sobre enfoques, contenidos, metodologías o curricula en la escuela, otra sobre el papel del maestro, o bien se revierta el orden de nuestro reflexionar: tal vez empezar por el lugar del docente pueda ayudarnos a poner orden en las ideas. En efecto, nos proponemos pensar en la "crisis", de manera que los indicadores de la misma puedan ser vistos más bien como piedras millares que nos marcan el camino. Un ejemplo: en el caso de los docentes, conocemos, entre los temas presentados en la prensa y en los discursos cotidianos, la queja de la opinión pública acerca de la efectividad del trabajo escolar, los famosos 200 días lectivos, la pertinencia de los Congresos de los trabajadores de la Escuela o, por el otro lado, los datos acerca de las incapacidades de los docentes, sus malestares psicofísicos, sus quejas en el ámbito profesional y personal. Puede ser que estos "emergentes" y otros nos marquen la vía y nos señales dónde preguntar, dónde existe la necesidad de comprender y de devolver las intuiciones, dónde las miradas, desde adentro y desde afuera, pueden representar el inicio de un cambio. 
Quien escribe opta por rechazar el llamado a la buena voluntad individual, el estudio de experiencias exitosas que nos quisieran señalar la entrega o "mística" individual de trabajadores señalados como la solución a los problemas que aquejan a la escuela en cuanto institución.

En pos de la claridad teórica, preferimos apartarnos de la tentación de referirnos a las consabidas referencias religiosas, como lo es el abusado término de vocación referido a la motivación o orientación profesional docente: creemos que los educadores no son sacerdotes y que su profesionalidad, conciencia social, la construcción de su biografía y de su noción de sí mismos son fruto de un recorrido específico en condiciones dadas. Vocación, en cambio, es un término que nos evoca un llamado desde arriba, un insondable destino que nos interpela desde afuera y desde más arriba de nuestra historia personal.

Probablemente aclararía más dirigir una mirada de conjunto a las mismas condiciones y contingencias que producen una respuesta tan masiva, crónica, como la que señala el recurso a las incapacidades por parte de los profesores y maestros.

De esta manera, nos vamos a referir a investigaciones y ensayos de teóricos internacionales y latinoamericanos, que se han interrogado sobre el tema del papel de los docentes en el mundo que cambia, desde la pedagogía crítica y otras posiciones, menos vinculadas a una postura teórica constituida.

Estas últimas, como la de la argentina Silvia Duschatzky, tienen la característica de provocarnos ansiedad, por la falta de un marco de referencia a priori y la tendencia a cuestionarnos más que a ofrecer respuestas. Aún así, los cuestionamientos son valiosos en un momento en que se tendrá que tomar una posición con respecto a reformas de la Escuela en un momento en que estamos todavía tratando 
de construir sentido para leer un entorno mundializado y empobrecido.

Todos los aportes teóricos citados, de diferente manera, contribuyen a la comprensión de los fenómenos y de sus contingencias, especificas y / o globalizadas, y dan pistas para escoger los puntos de partida para empezar a construir una escuela nueva, contando con el aporte indispensable de todos los actores sociales involucrados,

Peter Mc Laren (1986) es un representante de la pedagogía crítica que reflexiona acerca de la contingencia histórica que estamos viviendo, su complejidad y los cambios a los cuales conduce, estructurales y en el sujeto. Lamenta apasionadamente la ferocidad de la sociedad de consumo y las intenciones que la sostienen. Su preocupación y sentido de responsabilidad se dirigen especialmente hacia los adolescentes, víctimas de la brutalidad del mundo moderno, la glorificación del consumo, el achicamiento del Estado, la pérdida de la comunidad, el énfasis en el logro individual.

La investigación de Mc Laren toma en cuenta el papel de la ritualidad en la institución escolar. Para él, las escuelas, son instituciones estructuradas de manera intrincada y saturadas ritualmente, y funcionan como contenedores de sistemas simbólicos complejos. Los rituales desempeñan un papel importante no solamente en la vida de clase, sino en general en el encuentro pedagógico y parecen ser tan fundamentales para el programa del aula como para las materias de los propios cursos.

En las observaciones de McLaren, los ritos instruccionales servían para comunicar a los estudiantes mensajes codificados que, a su vez, servían tanto para promover funciones conductuales normativas como para diseñar marcos epistemológicos de dominio sobre los alumnos. En suma, los ritos instruccionales proporcionaban pistas tanto para 
"pensar" como para "hacer". Así, los estudiantes eran organizados para que pensaran acerca del mundo de cierta manera; eran motivados para actuar sobre el suyo propio de acuerdo con símbolos prescritos. Se pudo apreciar que los rituales del aula ni esclavizaban ni liberaban, alteraba la sensibilidad de los participantes y la creación de significado estuvo siempre sujeta a las restricciones materiales y a los contextos que rodeaban al ritual.

Los rituales instruccionales sirvieron fundamentalmente para santificar el lugar de trabajo, para cercar los terrenos culturales con tabúes, para apoyar el statu quo y crear un cuerpo del estudiante condicionado para aceptar ese estado de cosas. La escuela les ofrecía ayudarles a socializarse con valores y conductas "apropiados" colocándolos en áreas específicas y en cursos de nivel básico.

Los maestros son agentes y receptores en el contexto ritual complejo señalado. Había una fuerte tendencia, en ellos como en los estudiantes, a aceptar la "esclavitud" del trabajo escolar. Al menos uno de los maestros observados hizo intentos laudables por desarrollar en el estudiante una perspectiva crítica en cuanto al sufrimiento y la maldad en la sociedad moderna, intentos que generalmente se daban durante la clase de religión. Sin embargo, dado que esta materia era solamente una con las que llenaban la jornada escolar, las enseñanzas explícitas sobre religión tendían a verse aparte del resto de las áreas de estudio. La tendencia a aceptar que lo que se desprendía de los ritos instruccionales era sagrado e incuestionable ocurría en la enseñanza de todas las materias.

Es interesante destacar lo que en las investigaciones de Mclaren se aprende acerca del papel del maestro: los maestros aceptaban, propiciaban los rituales instruccionales, que eran experimentados como parte de un orden natural de cosas, de un marco socialmente aceptable de lo escolar. 
Los ritos instruccionales cotidianos transmitieron mensajes que no sólo eran singularmente no dialécticos sino que también abiertamente sobredistanciados. Lo que importaba era que los estudiantes siempre parecieran atareados, ocupados en el trabajo y 'atendiendo a la tarea". Mientras que algunos estudiantes crecían con los acrecentamientos procesales de los actos del ritual, otros sencillamente se aislaban y escogían "dejarse llevar" por el "ritmo" asignado a las actividades. Los ideales educativos eran constantemente saboteados y trastornados por hilos invisibles y por los contextos ideológicos de los ritos instruccionales que remplazaban el contenido académico. El maestro era como un coreógrafo de símbolos que no podía escapar de sus propios inventos.

Con una metáfora "astronómica" McLaren describe en el análisis final que se permitió que los estudiantes siguieran la estela de vapor resultante de corromper los símbolos que los maestros habían dejado decaer, y que aquellos cesaron de iluminar y se apagaron en el ocaso de la entropía.

El conocimiento es un estilo de conciencia, contenido y forma cultural. Es una manera de incorporar al conocimiento el sentido de la cultura que McLaren llama "de la esquina", aquella que los jóvenes construyen fuera del aula, en los espacios que se les otorga y/o que ellos se toman. Son estos espacios que es urgente incorporar a nuestra visión de la escuela, para otorgarle la importancia que merecen, y no en el sentido de ponerlos entre paréntesis en nuestra visión del "afuera" de la institución educativa, lo que no tiene que ver directamente con el trabajo que en ella se realiza.

Un señalamiento muy importante de McLaren, (1986, 1995), es el tema del uso de la cultura popular y la inserción del arte en la institución escolar, a lo largo de la jornada. El tema es importante por que alrededor de él se puede iniciar 
a delimitar nuevas propuestas curriculares y nuevos espacios para figuras profesionales docentes o de facilitadores. Al mismo tiempo, según el autor, debería tratarse de una técnica pedagógica o instruccional valiosa, para uso de los propios maestros en la enseñanza de todas las materias.

A través del arte y de la cultura popular podría orientarse todo el potencial de las actividades artísticas en la instrucción en general, mediante talleres de entrenamiento conducidos por maestros de teatro, teóricos del drama, ritólogos, teóricos del performance y otros expertos en arte. Podríamos agregarle expertos en retórica o expresión oral y otras figuras profesionales.

McLaren usa el término "cultura popular" y no se refiere al folklorismo refrito con el cual aburrimos a veces a nuestros estudiantes con la ilusión de presentarles las producciones artísticas válidas del pasado histórico de un pueblo. "Cultura" para el autor es el sitio histórico de lucha sobre la producción de los significados y "popular" es un término que quiere contrastar el de "cultura académica" o "cultura alta".

Por lo tanto, si nos interesa la cultura popular, más que las repeticiones acríticas de un pasado cultural que tal vez nunca existió, es importante promover las prácticas artísticas y las modalidades de difusión de los discursos que los estudiantes y la gente comúnmente conoce e intercambia. Esta, que es la "cultura popular" de McLaren, carga con su "popularidad", y sus productos suelen aparecer como

no académicos e indignos de investigaciones académicas y la gente estrechamente asociada a ellos es rápidamente menospreciada por indiscriminada y uulgar (1995, pag. 112)

Al considerar la cultura popular como lo trivial lo insignificante de la vida cotidiana, indigna de aparecer como 
material guía en le trabajo de aula, perdemos la posibilidad de analizarla críticamente, en sus sistemas amplios de relaciones sociales y fuertes intereses que la informan.

Servirá proponer un ejemplo, para vincular también el discurso con la realidad costarricense. Las telenovelas son los espectáculos televisivos que los preadolescentes costarricenses más ven, pero no se consideran material de aula y no se aprovecha de ellas. Sería útil, en cambio, si esta cultura popular de hoy, se usara como "gancho" en las clases y aquí los ejemplos son infinitos acerca de cómo utilizar ese conocimiento.

A un tiempo, aprovechando las risas y la atención que genera la apropiación de algo conocido y cercano como elemento de la metodología de la clase, se puede poner al desnudo el mensaje que vehiculan y observar la influencia que pueden tener en lo social. Para no caer en lo moralista, señalamos la importancia de consultar los materiales que consideran la telenovela como una forma de cultura que ha trascendido las fronteras y ha hecho conocer elementos de la vida latinoamericana en países muy lejanos y diferentes. Es posible también indicar que la telenovela nacional es un vehículo para sostener una incipiente industria cinematográfica en el país y el proceso de formación.

La sugerencia acerca de la incorporación de la cultura popular se retoma por que es central en las reflexiones sobre una escuela nueva, junto con la ampliación del espectro de las materias. Por lo contrario asistimos a su contracción en materias "académicas" y "especiales" o, peor aún, a la difusión de la ideología del "i.i.e." (Bertolini, 2003): inglés, informática, empresa, o escuela en la que los contenidos "novedosos" y "modernos" del idioma del Imperio y el manejo de los software y lenguajes informáticos empatan con el concepto de una escuela manejada como una empresa. 


\section{Educadores y reformas}

Entre las tareas de los docentes, está la de promover en los estudiantes la conciencia de que son sujetos corpóreos que interpretan el mundo no sólo en la cabeza y en el corazón, sino también en sus vientres y espaldas. Es importante aquí, sobre todo en el colegio, la conciencia de que la educación física, rescatando el nombre de la disciplina más que las tristes puestas en práctica que conocemos en los colegios, no es una "asignatura especial" más, y que los estudiantes no son cabezas hablantes, son personas enteras, adolescentes enfrentados con la difícil tarea de construcción de un sí mismo psicofísico, en la época del sexo como mercancía y de la reconstrucción de los papeles de género.

Giroux propone utilizar la expresión "discurso de democracia" para hacer referencia a la crítica y a un ideal que se basa en una visión dialéctica de la relación que media entre escuela y sociedad (1990). En este contexto las escuelas en crisis tiene que defenderse, defender y promover su función y papel potencial de lugares para la democracia crítica, vista como impulsora de la libertad individual a la vez que de la justicia social.

El papel del educador, en este contexto sería educar para el riesgo, para el cambio social. El discurso de la democracia crítica:

...apunta al papel que profesores y administrativos pueden desempeñar como intelectuales transformativos que desarrollan pedagogias contra hegemónicas, las cuales no solo potencian los estudiantes proporcionándoles el conocimiento y las habilidades sociales que necesitarán para actuar en el conjunto de la sociedad con sentido crítico, sino que, además, los educan para la acción transformadora. (Pág. 35) 
La acción se articula en diferentes planos: entre ellos emerge el de la relación con el currículum. No es común encontrar propuestas que articulen el tema del currículum escolar con el papel social del profesor. Para Giroux (1992) el currículum es la cultura social convertida en cultura escolar, por medio de las instituciones escolares y los profesores. Es, además, el eslabón entre la cultura y la escuela y se reflejan en él una opción cultural determinada y los esquemas socializadores que viven las comunidades educativas. El currículo tiene un sentido dinámico, de construcción cultural, social e histórica porque sólo cobra significado si está culturalmente contextualizado en sus elementos constitutivos. En este contexto, los profesores tienen la responsabilidad de ser mediadores e intermediarios de la cultura social.

Acerca de las tareas especificas del educador en el ámbito señalado, Giroux (1992) propone:

1. cartografiar el mundo en que las ideologías se inscriben en relación con la escolarización; 2 . ser crítico ante los currícula, las formas de organización escolar; 3. estar atento a cómo las ideologías son asumidas por los estudiantes; cómo dan cuerpo a los sueños, los deseos, las posiciones subjetivas de las personas en el institución escolar.

No se conoce mucha investigación sobre la lectura que los estudiantes realizan del mundo cargado ideológicamente en el que están inmersos. En lo particular, no se ha encontrado a nadie que en este momento, en Costa Rica, esté enfocando su investigación en la representación de los estudiantes y su relación con la ideología. Probablemente sea esa la más prometedora y próspera vías para entender el malestar del presente, lo que los diarios de difusión nacional llaman "deserción" escolar o los eventos que la misma 
prensa "grita" desde los titulares (D'Antoni, Induni y $\mathrm{Pa}$ checo, 2005).

Al contrario, establecer la mira en los jóvenes y sus lecturas del contexto significa prestar atención a las señales de malestar en cuanto a los elementos de comunicación: ese abordaje nos garantiza la presencia de un mundo latente de propuestas e invención. Los jóvenes responden ante la contingencia en la cual están inmersos, tienen su lectura del contexto y una idea de renovación de la escuela más acorde al realismo de la que tienen las autoridades ministeriales.

Cuando Giroux (1988, Pág. 109) advierte que "los educadores tendrán que servirse de valores, creencias, conocimientos de los alumnos como parte importante del proceso de aprendizaje" está afirmando algo que parece sabido, pero a la vez algo que no se aplica en las aulas. Escuchamos a diario en las comunicaciones ministeriales así como en nuestras aulas universitarias, en las cuales formamos a formadores, afirmaciones en contra de una educación "conductista" y a favor de una "constructivista" y recogemos una adhesión complacida a las teorías del Aprendizaje significativo y del Aprendizaje por descubrimiento, apenas atenuadas por las protestas relativas a la ausencia de recursos que no permitirían la implementación de los modelos indicados.

No puede haber aprendizaje por descubrimiento en un contesto de verticalidad, en el que no se reconoce que estudiantes y profesores tienen dificultades similares, problemas compartidos, anhelos y horizontes comunes. Todo esto ya que, dice siempre Giroux citando a Paulo Freire, el fin del pensamiento no es el conocimiento en sí, sino que lo es en un contexto mediador entre estudiante y profesor. No parece haber manera de realizar esa mediación en un lugar en el que la relación estudiante / profesor está viciada por contradicciones de fondo, por la asunción y la defensa por parte de los profesores de un proyecto educativo y, en 
fin de cuentas, político que no pertenece a sus intereses, los enajena y los conduce a reproducir esa enajenación en el aula.

El malestar por parte de los estudiantes se expresa en resistencia: las eternas rebeliones acerca del uniforme y de la expresión personal del cuerpo, por ejemplo. El de los docentes puede ser reflejado en la cultura de la interrupción, el alargamiento de los recreos, el número exorbitante de incapacidades solicitadas, algunos aspectos de la ritualización de McLaren trasportados en contexto costarricense.

\section{Conclusiones}

La escuela en este momento muestra ser, más allá de las obvias protestas y de los textos críticos sabidos, una instancia en la que verdaderamente actúan las ideologías y prácticas de dominación. Es un centro de reproducción social, pensado para producir trabajadores obedientes para el capital industrial, con la desventaja ulterior de la miopía con la cual el poder dominante no logra siquiera adaptar la escuela al formato renovado que el nuevo capitalismo requeriría y, como se ha visto, se ha propuesto resumir en los tres términos de inglés, informática, empresa (Bertolini, 2003).

Tenemos, a la par de las modas que instan a considerar la escuela una empresa que puede generar parte de los recursos que requiere, inspiraciones para construir nuevos modelos pedagógicos más adherentes a los tiempos y sus necesidades.

Las reformas que vemos actuarse o prepararse en diferentes partes del mundo, Costa Rica incluida, sufren de varias carencias. Una de ellas, bastante grave, es la de no atreverse a incluir en agenda la experiencia de los educadores.

Los educadores mismos se están evidenciando de manera muy tímida en calidad de expertos y parte en causa 
de posibles reformas educativas. En Costa Rica son poco ayudados en esta tareas por instancias, como las sindicales o colegiales, que probablemente están más interesadas en asuntos corporativos internos y de defensas de condiciones contractuales que en revisar, junto con otros actores de la escuela su papel en un panorama que aspectos de riesgo pero es a la vez prometedor de cambio.

\section{BIBLIOGRAFÍA}

Bertolini, Piero (2003) Educazione e politica. Raffaello Cortina Editore, Milán

Corea, Cristina y Duschatzky, Silvia (2002) Chicos en banda. Los caminos de la subjetividad en el declive de las instituciones. Paidós, Buenos Aires

Castells, Manuel y otros (1994) Nuevas perspectivas críticas en educación. Paidós Educador, Barcelona.

D'Antoni, Maurizia; Induni, Gina y Pacheco, Xenia. (2005) Crisis en la educación secundara. ¿Reproducir o transformar? En: Revista Educare. N.8 Universidad Nacional. Centro de Investigación y Docencia en Educación, EUNA, Heredia.

Elliott, John (1991) Action research for educational change. Open University Press, Reino Unido

Giroux, Henry (1990). Los profesores como intelectuales. Hacia una pedagogía crítica del aprendizaje. Paidós, Madrid

Id (1992) Cruzando límites. Trabajadores culturales y políticas educativas. Paidós Educador, Barcelona.

Jameson, Fredrick y_i_ek, Slavoj (1997) Estudios culturales. Reflexiones sobre el multiculturalismo. Paidós, Buenos Aires.

Mc Laren, Peter (1986) La escuela como un performance ritual. Hacia una economía política de símbolos y gestos educativos. Siglo XXI Editores, Ciudad de México.

Id. (curador) (1995) Pedagogía, identidad y poder. Los educadores del multiculturalismo. Homo Sapiens, Argentina\}

Proyecto Estado de la Nación en Desarrollo Humano Sostenible. (2004) XI Informe Estado de la Nación en Desarrollo Humano Sostenible. Programa Estado de la Nación. San José, Costa Rica

Grüner, Eduardo (1998). "El retorno de la teoría crítica de la cultura: una introducción alegórica a Jameson y _i_ek". En: Jameson, 
Fridrick y_i_ek, Slavoj. Estudios culturales. Reflexiones sobre el multiculturalismo. Paidós, Buenos Aires. 